Short report

\title{
Familial autoimmune myasthenia gravis with different pathogenetic antibodies
}

\author{
CARLO PROVENZANO,* OTTAVIO ARANCIO, $\dagger$ AMELIA EVOLI, \\ BIANCA ROCCA,* EMANUELA BARTOCCIONI,* DOMENICO DE GRANDIS, $\dagger$ \\ PIETRO TONALI \\ From the Institutes of General Pathology* and Neurology, $\ddagger$ Catholic University of Rome, and Institute of \\ Neurology, $\uparrow$ University of Verona, Italy
}

SUMMARY Two cases of familial myasthenia gravis are reported. One patient is a typical case of autoimmune myasthenia with positive anti acetylcholine receptor antibodies, while in the second patient the impairment of neuromuscular transmission is likely to be due to antibodies directed against determinants other than the acetylcholine receptors.

Acquired myasthenia gravis (MG) is usually a sporadic autoimmune disease due to antibodies directed against the nicotinic acetylcholine receptor (AChR) at the neuromuscular junction. ${ }^{12}$ Congenital myasthenic syndromes have a different, non autoimmune, pathogenesis. ${ }^{3}$ Familial cases are reported in both the acquired and the congenital forms of $\mathbf{M G}$, but more frequently in the latter type of the diseases. $^{45}$

We report two cases of autoimmune MG occurring in the same family; in these patients, the same pathogenetic mechanism (an autoimmune attack against the neuromuscular junction) is likely to be directed at two different targets.

\section{Case reports}

Case 1

Father, born in 1935. This patient has been suffering from mild generalised MG (2A according to Osserman) since 1955. Symptoms had always been typical; Tensilon test, repetitive supramaximal stimulations and anti $\mathrm{AChR}$ antibodies (assayed for the first time in 1980, as previously described $^{6}{ }^{7}$ ) were clearly positive. Thymectomy was performed within one year from onset, with removal of a hyperplastic thymus. As anticholinesterase drugs (AChE) were very effective in controlling the symptoms, immunosuppressive treatment was never required. At present, the patient is nearly asymptomatic, receiving pyridostigmine. HLA typing for DR and DQ revealed the following haplotype: DR2 DR5 DQw1.

Address for reprint requests: Dr C Provenzano, Department of Chemical Immunology, The Weizmann Institute of Sciences, $\mathbf{7 6 1 0 0}$ Rehovot, Israel.

Received 8 January 1988 and in revised form 28 April 1988. Accepted 4 May 1988
Case 2

Son, born in 1965. The onset of the disease was in 1980, with intermittent diplopia together with nasal speech, exertional dyspnoea and inspiratory stridor due to incomplete paralysis of vocal cords. Tensilon test was weakly but clearly positive, while $3 \mathrm{~Hz}$ repetitive supramaximal stimulation test showed $11 \%$ decrement on the 5th stimulus, which in our experience is the upper limit of normal controls. ${ }^{8}$ Repeated assays for anti AChR antibodies directed against sites other than the alpha-bungarotoxin binding site (measured as in case 1) or against the toxin binding site (tested according to Besinger ${ }^{9}$ ) gave negative results, even when increasing serum concentrations were used. Thymectomy was performed 3 monthsc after the onset of the disease and a normal thymus was removed. As AChE had not been very effective, prednisone treatment was started in 1984 with mild improvement. The patient's symptoms remained quite stable until 1986, when he suffered from a severe respiratory distress due to complete vocal cords paralysis. Tracheostomy was thus required, following which the patient was submitted to 11 plasmaexchange courses with marked improvement. Now he is in good condition under prednisone treatment. HLA typing for DR and DQ revealed the following haplotype: DR2 DR10 DQw2.

Clinical examination and anti $\mathrm{ACh}$ antibody assays were negative in the three brothers of case 2 .

\section{In vitro neuromuscular transmission}

IgG fraction was purified from plasma-eschange bags by the Rivanol-ammonium sulphate method. ${ }^{10} \mathrm{Balb} / \mathrm{c}$ female mice were injected intraperitoneally for 3 days with $40 \mathrm{mg}$ of purified test IgG from case 2 each day; on the 4th day, mice were killed, the diaphragms were removed and examined at constant temperature $\left(25^{\circ} \mathrm{C}\right)$ during continuous perfusion with Rees solution ${ }^{11}$ bubbled with $95 \% \mathrm{O}_{2} 5 \% \mathrm{CO}_{2}$. Isometric contraction was examined fixing one end of the muscle by means of its ribcage attachment and the other by the central tendon to a tension transducer (Ugo Basile Isometric Transducer 7005), connected to a Tektronix equip- 
ment (5A22N Differential Amplifier and 5111 Storage Oscilloscope). The nerve was raised into a layer of liquid paraffin and placed on a pair of platinum electrodes for stimulation. Negative controls were both untreated and normal human IgG fraction treated animals (intraperitoneally injected with $80 \mathrm{mg}$ of purified IgG from healthy blood donors for 5 days); positive control mice were injected with purified IgG from AChR antibody positive patients (40 $\mathrm{mg}$ intraperitoneally for 3-4 days).

Trains of seven supramaximal stimuli were applied every 3 minutes for at least $\mathbf{3 0}$ minutes to confirm the stability of the response in Rees solution; then, D-tubocurarine was added to the solution (final concentration: $0.8 \mu \mathrm{g} / \mathrm{ml}$ ) for 30 minutes, during which stimulus trains were applied every 3 minutes; finally, perfusing solution was changed back to Rees alone, and stimulation was continued until significant decrement was no longer observed. In normal Rees solution there was no significant difference between control and test mice for the initial twitch tension of the first stimulus of each train; no significant decrement (measured as the percentage fall in amplitude of the fifth response compared to the first in the same train) was present both in test and control mice. The addition of curare caused a decrement of $5 \cdot 7$, SD $3 \cdot 2 \%$ in negative control mice ( 21 measurements in five animals), a decrement of 57.8 , SD $19 \cdot 2 \%$ in positive control mice $(19$ measurements in four animals) and a decrement of $32 \cdot 1$, SD $16.4 \%$ in test mice (11 measurements in two animals; $\mathrm{p}<<0.001$ with respect to negative controls).

End-plate AChR loss was measured in the same hemidiaphragms used for electrophysiological tests as previously described, ${ }^{12}$ using Rees instead of Ringer solution. Receptor loss in two mice was $18.7 \%$ when compared to negative controls, which is comparable with that found in some of their cases by Mossman et al. ${ }^{12}$

\section{Discussion}

The incidence of familial cases in MG is estimated to be about $3 \%,{ }^{45}$ their pathogenesis being either congenital or autoimmune. In our series of $423 \mathrm{MG}$ patients we found six familial cases: two of them (sister and brother) were affected by a congenital myasthenic syndrome, with onset at birth and negative anti AChR antibodies; two sisters had autoimmune MG with onset in their teens and high anti AChR antibody titres. The two cases here reported, father and son, are affected by autoimmune MG. Case 1 is a typical case of autoimmune MG, both in his clinical and immunological characteristics; in contrast, his son (case 2) raises some diagnostic difficulties on account of the atypical course of the disease, the poor response to $\mathrm{AChE}$, the absence of detectable anti AChR antibodies and the equivocal electromyographic data. A congenital myasthenic syndrome is unlikely on account of the late onset of the disease and the positive response to immunosuppressive drugs and plasma-exchange; the Lambert Eaton myasthenic syndrome can be ruled out by the presence of brisk tendon reflexes and the absence of the typical electromyographic findings. ${ }^{3}$ On the other hand, the marked improvement after plasma-exchange implies the presence of some circulating factor responsible for the disease. Using a passive transfer model coupled to an in vitro electrophysiological technique we were able to demonstrate that the pathogenic factor in this patient belongs to the IgG fraction, thus suggesting the presence of an autoimmune mechanism also in patient 2 . In this respect this case is similar, both in the clinical and immunological features, to some of those reported by Mossman et al: ${ }^{12}$ these authors first demonstrated the presence of circulating antibodies directed against antigens at the neuromuscular junction other than the AChR by means of an electrophysiological technique similar to the one described here. The interest of our two cases resides in the fact that the autoimmune response is very likely to be directed against different targets: the AChR in case 1, a still unidentified component of the neuromuscular junction in case 2. Both patients express the HLADR2 antigen, the increased frequency of which in older-onset MG patients have already been described; ${ }^{13}{ }^{14}$ this finding reinforces the hypothesis of a common mechanism, that is, an alteration of self tolerance, in the disease pathogenesis of our two cases. The two antigens involved can account for the different clinical courses in these patients.

We thank Dr Angela Vincent, the Royal Free Hospital of London, for reassaying the serum of case 2 confirming our data and for valuable help in writing this paper. We thank Drs R Manna and M Salvatore for HLA typing. This work was supported by grants Ministero Publica Istruzione $60 \% \mathrm{n}^{\circ} 71460$ and 70400 .

\section{References}

I Lindstrom J, Seybold ME, Lennon VA, Wittingham S, Duane DD. Antibody to acetylcholine receptor in myasthenia gravis. Neurology 1976;26:1054-9.

2 Vincent A, Newsom-Davis J. Anti-acetylcholine receptor antibody. $J$ Neurol Neurosurg Psychiatry 1980;43:590-600.

3 Engel AG. Myasthenia gravis and myasthenic syndromes. Ann Neurol 1984;16:519-34.

4 Namba T, Brunner NG, Brown SB, Muguruma M, Grob D. Familial myasthenia gravis. Arch Neurol 1971;25:49-60.

5 Oosterhuis HJGH. Myasthenia gravis. Edinburgh: Churchill Livingstone, Clinical Neurology and Neurosurgery Monographs 1984:45-50.

6 Lindstrom J. An assay for antibodies to human acetylcholine receptor in serum from patients with myasthenia gravis. Clin Immunol Immunopathol 1977;7:36-43.

7 Bartoccioni E, Scuderi F, Scoppetta C, et al. Myasthenia gravis, thymectomy and antiacetylcholine receptor antibody. $J$ Neurol 1980;224:9-15. 
8 Scoppetta C, Tonali P, Lo Monaco M, Vaccario ML. Tests elettrofisiologici nella miastenia. Riv Ital Elettroencef Neurofisiol 1979;1:117-22.

9 Besinger UA, Toyka M, Homberg M, Heininger K, Holhfeld R, Fateh-Moghadam A. Myasthenia gravis: long-term correlation of binding and bungarotoxin blocking antibodies against acetylcholine receptor with changes in disease severity. Neurology 1983;33:1316-21.

10 Heide K, Schwick HG. Salt fractionation of immunoglobulins. In: Weir DM, ed. Handbook of Experimental Immunology, 3rd ed. 1978 Oxford: Blackwell.

11 Rees D. A non-phosphate-buffered physiological saline for in vitro electrophysiological studies on the mammalian neuromuscular junction. $J$ Physiol (Lond) 1978;278:8P-9P.

12 Mossman S, Vincent A, Newsom-Davis J. Myasthenia gravis without acetylcholine-receptor antibody: a distinct disease entity. Lancet 1986;i:116-9.

13 Compston DA, Vincent A, Newsom-Davis J, Batchelor JR. Clinical, pathological, HLA antigen and immunological evidence for disease heterogeneity in myasthenia gravis. Brain 1980;103:579-601.

14 Newsom-Davis J, Willcox N, Schluep M, et al. Immunological heterogeneity and cellular mechanisms in myasthenia gravis. Ann NY Acad Sci 1987;505:12-26. 